BANGLADESH J CHILD HEALTH 2011; VOL 35 (2): 49-52

\title{
Detection of Antinuclear Antibody in Childhood Rheumatic Diseases by Immunofluorescence Assay and Enzyme Immuno Assay
}

\author{
TANJEEM RABIKADIPTI ${ }^{1}$, MOHAMMAD SHAIFUL AZAM ${ }^{1}$, MOHAMMAD HUMAYUN SATTAR ${ }^{2}$, \\ SHAHANAARAHMAN ${ }^{3}$
}

\begin{abstract}
Background: Anti-nuclear antibodies (ANAs) are specific antibodies directed against a variety of nuclear antigens. Indirect immunofluorecence (ANA-IFA) and Enzyme Immunoassay (ANA-EIA) are commonly used methods for ANA detection. The positivity of ANA-IFA using HEp-2 cell substrate is $90-100 \%$ in systemic rheumatic diseases. On the other hand positivity of ANA-EIA is found to be much lower in different studies. In Bangladesh most of the laboratories use ANA-EIA method.
\end{abstract}

Objectives: To detect ANA by Immunofluorecence Assay (using HEp-2 cell substrate) and Enzyme Immuno Assay in childhood rheumatic diseases and to compare ANA positivity by these two methods.

Materials and methods: Cross sectional comparative study. Total 40 patients of different childhood rheumatic diseases were enrolled in this study. Serum sample was collected and tested for detection of ANA by Immunofluorecence Assay using HEp-2 cell substrate and Enzyme Immuno Assay.

Result: Among total 40 cases, $67.5 \%$ were ANA positive by IFA method and $27.5 \%$ were ANA positive by EIA method.

Conclusion: ANA-IFA is superior to ANA-EIA for detection of ANA in childhood rheumatic diseases.

Key words: Antinuclear Antibodies, Immunofluorescence Assay, Enzyme Immuno Assay, Childhood rheumatic diseases.

\section{Introduction}

Rheumatic diseases in children results from autoimmune processes that lead to inflammation of target organs ${ }^{1}$. As different organs may be affected, rheumatic disease must be considered for a wide range of presenting complaints ${ }^{2}$. Childhood rheumatic diseases are important cause of morbidity and mortality. But in the last century due to advent of newer treatment modalities dramatic improvement occurred in the management of childhood rheumatic diseases ${ }^{1}$. Early and effective diagnosis causes good prognosis ${ }^{3}$. So diagnosis of a child with rheumatic disease is a

1. Pediatrician, Bangabandhu Sheikh Mujib Medical University (BSMMU), Shahbagh, Dhaka, Bangladesh

2. Professor, Department of Microbiology and Immunology, Bangabandhu Sheikh Mujib Medical University (BSMMU), Shahbagh, Dhaka, Bangladesh

3. Professor, Department of Paediatrics, Bangabandhu Sheikh Mujib Medical University (BSMMU), Shahbagh, Dhaka, Bangladesh

Correspondence: Tanjeem Rabika Dipti challenge for a pediatrician and should be individualized to yield the maximum information with minimum cost and discomfort ${ }^{4}$

Anti-nuclear antibodies (ANAs) are specific antibodies directed against a variety of nuclear antigens those have been detected in the serum of patients with many rheumatic and non rheumatic diseases. These antibodies are involved not only in the disease pathogenesis, but they also constitute the basis for diagnosis and treatment of childhood rheumatic diseases like Systemic Lupus Erythematosus (SLE), Juvenile Idiopathic Arthritis (JIA), Systemic sclerosis (SSc), Poly Arteritis Nodosa (PAN) etc ${ }^{5}$. The ANA test is $95-100 \%$ sensitive for the diagnosis of $\mathrm{SLE}^{6}$. It is also useful in diagnosis -of JIA. Among all types of JIA, ANA positivity is highest $(65 \%-85 \%)$ in oligoarticular type. ANA positivity in JIA patient is a risk factor for development of uveitis ${ }^{1}$. SSc and PAN 
patients might also have ANA positivity in about $80 \%$ and $25 \%$ cases respectively 1,7 .

There are different methods for detection of ANA. Indirect immunofluorecence (ANA-IFA) and enzyme immunoassay (ANA-EIA) are commonly used methods. The sensitivity of ANA-IFA using HEp-2 cell substrate is $90-100 \%$ in systemic rheumatic diseases $^{5}$. In Bangladesh most of the laboratories use ANA-EIA for ANA detection. As because sensitivity of ANA-EIA is lower than ANA-IFA, it might happen that we are missing many cases of ANA positivity in childhood rheumatic diseases.

The present study was done with the objectives of detection of ANA by immunofluorecence assay using HEp-2 cell substrate and enzyme immunoassay in childhood rheumatic diseases. This study also compared ANA positivity by these two methods.

\section{Materials and methods}

This cross sectional comparative study was conducted in the department of Paediatrics, Bangabandhu Sheikh Mujib Medical University (BSMMU) from January 2009 to April 2010. Ethical clearance was taken from the department ethical clearance committee before study. Total 40 patients of childhood rheumatic diseases were enrolled in this study. Among them 20 were SLE cases, 18 were oligoarticular JIA cases and 2 were PAN cases. ACR (American College of Rheumatology, 1997) set criteria was applied as gold standard for diagnosis of SLE patients ${ }^{2}$, ILAR (International league Against Rheumatism) classification criteria for oligoarticular $\mathrm{JIA}^{1}$ and ACR (1990) classification criteria for polyarteritis nodosa (PAN) patients ${ }^{1}$ were used for diagnosis. A preformed structured questionnaire was used for data collection. Written consent was taken from the parents before enrollment of their children in the study. Prior to that they were informed about the nature of the study. Fund for ANA detection by both the method was provided by the investigator themselves. Five ml (5) of venous blood was collected in a clean test tube and allowed to clot naturally. Serum was separated and stored at -20 degree Celsius prior to ANA assay. In this study IMTECHEp-2 KIT was used to detect ANA by immunofluorecence method using HEp-2 cell line as substrate. Standard dilution for ANA by IFA is $1: 40^{5}$.
In the present study 1:40 dilution was considered positive for detection of ANA by IFA method. Positive and negative control serum were provided with HEp2 cell reagent for IFA. Any test serum showing fluorescence intensities equivalent to or more than positive control was considered positive and any test serum showing intensity below positive control was considered negative. Fluorescence intensities were determined and recorded by a single expert. The BINDAZYME tm ANA screen Enzyme Immunoassay kit was used in this study to detect ANA by EIA. ANA results by both methods were categorized into positive and negative. Data were analyzed manually and positivity of ANA-IFA and ANA-EIA was measured. Comparison between positivity of two methods was done statistically using the Fisher exact test and $p$ value $<0.05$ was considered significant.

\section{Result}

Table-I shows that among 40 childhood rheumatic patients $20(50) \%$ were SLE cases, $18(45 \%)$ were oligoarticular JIA cases and $2(5 \%)$ were PAN patients.

Table-I

Types of childhood rheumatological disease among study population $(n=40)$

\begin{tabular}{lcc}
\hline Types & Number & Percentage $(\%)$ \\
\hline Childhood SLE & 20 & 50 \\
Oligoarticular JIA & 18 & 45 \\
Polyarteritis Nodosa & 2 & 5 \\
\hline Total & 40 & 100 \\
\hline
\end{tabular}

Table-II shows that among 40 childhood rheumatological diseases patients, $67.5 \%$ patients were ANA positive by IFA method and $27.5 \%$ patients were ANA positive by EIA method and $5 \%$ patients were found to be ANA negative by both methods. This difference was found to be highly significant. ANA by IFA was positive in $100 \%$ SLE cases, $33 \%$ oligoarticular JIA cases and $50 \%$ PAN patient. On the other hand, ANA by EIA was positive in 55\% SLE cases. No cases of oligoarticular JIA and PAN had ANA positivity by EIA method. 
Table-II

Comparison of ANA positivity in childhood rheumatological diseases by ANA-IFA and ANA-EIA methods.

\begin{tabular}{llll}
\hline $\begin{array}{l}\text { Childhood rheumatological } \\
\text { diseases }(\mathrm{n}=40)\end{array}$ & $\begin{array}{l}\text { ANA positivity by } \\
\text { Immunofluorecence method }\end{array}$ & $\begin{array}{l}\text { ANA positivity by Enzyme } \\
\text { Immuno method }\end{array}$ & p value \\
\hline SLE $(\mathrm{n}=20)$ & $20(100 \%)$ & $11(55 \%)$ & 0.001 \\
Oligoarticular JIA $(\mathrm{n}=18)$ & $6(33 \%)$ & $0(00)$ & 0.019 \\
PAN $(\mathrm{n}=2)$ & $1(50 \%)$ & $0(00)$ & 0.99 \\
\hline Total $(\mathrm{n}=40)$ & $27(67.5 \%)$ & $11(27.5 \%)$ & 0.0007 \\
\hline
\end{tabular}

\section{Discussion}

There are several methods of ANA detection. Among them ANA-IFA and ANA- EIA are widely used. Most of the laboratories in the world use ANA-IFA using HEp2 cell substrate which is the gold standard method for detection of ANA in systemic rheumatic diseases ${ }^{5}$.

This cross sectional comparative study was done to detect ANA positivity in childhood rheumatic diseases by ANA-IFA and ANA-EIA methods. Many studies were conducted in different countries to detect the superior methods for detection of ANA in systemic rheumatic diseases like SLE, SSc, JIA, PAN, Mixed Connective Tissue Disorders etc ${ }^{8-14}$. ANA positivity by IFA method was found in $67.5 \%$ cases in the study. ANA positivity by EIA method was $27.5 \%$ patients and $5 \%$ patients were found to be ANA negative by both the methods (Table-II2). Differences of ANA positivity by these two methods were highly significant ( $p$ value $<0.0007$ ).

ANA positivity by IFA method was found in $100 \%$ SLE cases (Table 2). El-Chennawi et al ${ }^{8}$ also found similar result where IFA detected ANA in $100 \%$ cases of SLE. Other reported series also found similar results 5,15 ANA positivity by EIA method was found as $55 \%$ among SLE cases which was much lower than ANAIFA method. This difference of ANA positivity by two methods was highly significant ( $p$ value $<0.001$ ). This finding is very alarming, because by ANA-EIA method there was chance of missing about $45 \%$ ANA positivity in SLE patients.

The present study found ANA-IFA positivity in 33\% cases of oligoarticular JIA (Table-2). It is documented that ANA by IFA has highest positivity $(65 \%-85 \%)$ in children who have oligoarthritis and uveitis. Therefore, determination of ANA seropositivity is supportive of the diagnosis and important in identification of children most at risk for uveitis, so that early detection and prevention of uveitis can be done. At the present, tests for ANAs are mostly performed on the Hep-2 cell line ${ }^{1}$. Nandi et al $^{16}$ in their study found ANA- IFA positivity in $10 \%$ cases of oligoarticular JIA and they concluded that uveitis and presence of ANA was found to be rare in Indian children. In the present study ANA positivity was much lower than documented findings but higher than Nandi et al study. It may be explained by different rate of ANA positivity in different ethnic group ${ }^{16}$.On the other hand, none of the oligoarticular JIA cases was ANA positive by EIA method. Fenger et al ${ }^{10}$ reported that EIA method cannot detect the presence of ANA in JIA. Findings of the present study is in agreement with that report. So, ANA-IFA method is recommended from the current study for detection of ANA.

The present study found ANA positivity by IFA method in 1 PAN case $(50 \%)$ among 2 PAN patients (Table2) that differs from Cassidy and Petty ${ }^{1}$ where they found $25 \%$ ANA positivity by IFA in childhood PAN patients. The probable explanation for this difference could be due to very small number of PAN patients in this study.

\section{Conclusion}

Though sample size was small, it may be concluded from this study that detection of ANA by Immunofluorecence Assay using HEp-2 cell substrate is much superior than Enzyme Immuno Assay in childhood rheumatological diseases.

\section{Limitation:}

Sample size was small due to financial constraint.

\section{References:}

1. Cassidy JT, Petty RE. Introduction to the study of rheumatic diseases in children.In: Cassidy JT, Petty Re, Laxer RM, Lindsley CB editors. Textbook of Pediatric Rheumatology. Philadelphia: W.B. Saunders company; 2005. p. 2-7. 
2. Miller ML. Evaluation of Suspected Rheumatic disease. In: Kliegman RM, Behrman RE, Jenson HB, Stanton BF editors. Nelson Textbook of Paediatrics, Philadelphia: W.B. Saunders company; 2008. p. 995-7.

3. Paut IK, Piram M, Guillaume S, Tran TA. Review: Lupus in adolescence. Lupus 2007; 16: 606-12.

4. Aggarwal A. Clinical Application of Tests Used in Rheumatology. Indian Journal of Pediatrics 2002; 69(10): 889-92.

5. Kumar Y, Bhatia A, Minz RW. Antinuclear antibody and their detection methods in diagnosis of connective tissue diseases: a journey revisited. Diagnostic Pathology 2009; 4: 1-10.

6. Kavanaugh A, Tomar R, Reveille J, Solomon DH, Homburger HA. Guideline for Clinical Use of the Antinuclear Antibody Test and test for specific autoantibodies to nuclear Antigens. Arch Pathol Lab Med 2000; 124: 71-81.

7. Wanchu A. Review: Making the diagnosis of Systemic Lupus Erythematosus in children and adolescents. Lupus 2007;16(8): 546-9.

8. El-Chennawi FA, Mosaad YM, Habib HM, Eldegheidi T. Comparative Study of Antinuclear Antibody Detection by Indirect Immunofluorecence and Enzyme Immunoassay in Lupus Patients. Immunological Investigations 2009; 38(8): 839-50.

9. Yilmaz O, Karaman M, Ergon MC, Bahar IH, Yulug N. Comparison of indirect immunofluorecence and enzyme immunoassay methods for determination of antinuclear antibodies. Mikrobiyol Bul 2004; 38 (1-2): 85-90.
10. Fenger M, Wiik A, Madsen M, Lykkegaard J, Rozenfeld T, Hansen MS et al. Detection of Antinuclear Antibodies by Solid-Phase immunoassay and Immunofluorescence Analysis. Clinical Chemistry 2004; 50: 2141-7.

11. Tonutti E, Bassetti D, Piazza A Visentini D, Poletto M, Bassetto $F$, et al. Diagnostic accuracy of Elisa Methods as an Alternative Screening Test to Indirect Immunofluorescence for the Detection of Antinuclear antibodies: Evaluation of five Commercial Kits. Autoimmunity 2004; 37(2): 171-6.

12. Solomon DH, Kavanaugh AJ, Schur PH and The American College of Rheumatology AD HOC Committee on immunologic testing guidelines. Evidence- Based guidelines for the Use of Immunologic Tests: Antinuclear Antibody Testing. Arthritis and Rheumatism 2002; 47(4): 434-44.

13. Hayashi N, Kumagai S. Immunofluorescencestill the 'gold standard' in ANA testing. Scand J Clin Lab Invest 2001; 61: 77-83.

14. Hayashi N, Kawamoto T, Mukai M, Morinbobu A, Koshiba M, Kondo S, et al. Detection of Antinuclear antibodies by Use of an enzyme Immunoassay with Nuclear HEp-2 Cell Extracts and Recombinant Antigens: Comparison with Immunofluorescence Assay in 307 Patients. Clinical Chemistry 2001; 47(9): 1649-59.

15. Gill MJ, Quisel AM, Rocca P, Walters DT. Diagnosis of Systemic Lupus Erythematosus. Am Fam Physician 2003; 68(11): 2179-87.

16. Nandi M, Rekvig OP. Clinico-Serological Profile of Juvenile idiopathic Arthritis. Indian Pediatrics 2009; 46: 640-1. 